\title{
International approaches to the prescription of long-term oxygen therapy
}

\section{To the Editor:}

We read with interest the article by WIJKSTRA et al. [1], in which the authors described the results of an international survey that was undertaken to compare how respirologists prescribed oxygen. I would like to contribute to the area of oxygen prescriptions and share the experience gained at a tertiary referral hospital in Turkey.

In Turkey, we require patients to be in a sitting position during testing and the resting arterial oxygen saturation $\left(\mathrm{Sa}_{\mathrm{a}} \mathrm{O}_{2}\right)$ to be $90 \%$. We generally prefer to prescribe the resting flow during sleep, but in some instances, we test the patients individually. We prefer to individualise oxygen during exercise by testing each patient whilst walking and aim to achieve an $\mathrm{Sa}_{2} \mathrm{O}_{2}$ of $90 \%$ during exercise. Although flow rates are individualised in most instances, there may be institutional differences in Turkey too. These differences occur because current national and European guidelines do not provide specific recommendations about oxygen prescription during exercise [2]. Clinicians do not have evidence indicating the $\mathrm{Sa}_{\mathrm{a}} \mathrm{O}_{2}$ most likely to optimise the benefits of long-term oxygen therapy (LTOT) for their patients. Clinicians prescribe oxygen during sleep for patients who have resting hypoxaemia. Among respirologists in Turkey, there may also be substantial differences with regard to how oxygen is prescribed during sleep. These differences may be related to the fact that there are no guidelines for night prescription in our country. Standardisation of the LTOT prescription is an important issue [3].

As liquid oxygen use is very limited in Turkey, costs are much lower than those of countries involved in this survey. The exact number of patients receiving oxygen in Turkey is not known as, to date, there is no national registry. In a study aimed at investigating the prescription and usage of LTOT in the form of an oxygen concentrator at one of the largest tertiary referral chest hospitals in Turkey, we reviewed 114 patients in whom oxygen concentrators were prescribed between July 1998-December 2000 [4]. We found oxygen to be appropriately prescribed in $85 \%$ of patients. A compliance survey was set up in a sample of patients who replied to a postal invitation and $46 \%$ were contacted. Of the responders, only $42 \%$ were using oxygen $\geqslant 15 \mathrm{~h} \cdot \mathrm{day}^{-1}$. It was concluded that the majority of LTOT patients fulfilled the prescription criteria. However, routine follow-up of the patient's oxygenation and compliance was often inadequate even at a tertiary referral centre as no follow-up plans, either regular home or hospital visits, are in action in our healthcare system.

It is recommended that in order to keep this therapy cost-effective and beneficial, all long-term oxygen therapy patients should be re-evaluated in a timely fashion and should receive a close follow-up by experienced healthcare personnel to improve compliance. We agree that this survey highlights the potential for consensus conferences and multicentre studies to improve the effectiveness of long-term oxygen therapy use, while minimising the cost of domiciliary oxygen programmes.

\section{Tor*,\#, H. Turker ${ }^{\#}$}

*Dept of Pulmonary Medicine, Faculty of Medicine, Zonguldak Karaelmas University, Zonguldak and "Sureyyapasa Centre for Chest Diseases and Thoracic Surgery, Istanbul, Turkey.

\section{References}

1. Wijkstra PJ, Guyatt GH, Ambrosino N, et al. International approaches to the prescription of longterm oxygen therapy. Eur Respir J 2001; 18: 909-913.

2. Siafakas NM, Vermeire P, Pride NB, et al. Optimal assessment and management of chronic obstructive pulmonary disease (COPD). Eur Respir J 1995; 8: 1398-1420.

3. Zielinski J. Current status of home oxygen therapy in various countries. Criteria and indications for home oxygen therapy. In: Kira S, Petty TL, eds. Progress in Domiciliary Respiratory Care - Current Status and Perspective. Amsterdam, City Elsevier Science BV, 1994; pp. 3-98.

4. Tor M, Karakurt Z, Turker H, Sulu E, Yazicioglu O, Arslan S. Analysis of oxygen concentrator prescriptions and problems in follow-up at a tertiary referral hospital in Turkey. Eur Respir J 2001; 18: Suppl. 33, 390S, P2666. 